\title{
HPTLC Fingerprinting in the Standardization of Panchavaktra Ras: A Herbo-Mineral Preparation
}

\author{
Research article
}

\section{Srinivasulu Bandari ${ }^{*}$, Bhadra Dev $\mathbf{P}^{2}$, Murthy P H C ${ }^{3}$}

1. P.G.Scholar 2. Supervisor, Professor \& Head, 3.Co-Supervisor, Gazetted-Lecturer, PG Dept. of Rasa-Shastra, Dr.N.R.S.Govt. Ayurvedic College, Vijayawada, Andhra Pradesh

\begin{abstract}
High performance thin layer chromatography (HPTLC) is an enhanced form of thin layer chromatography (TLC). A number of enhancements can be made to the basic method of thin layer chromatography to automate the different steps, to increase the resolution achieved and to allow more accurate quantitative measurements. Automation is useful to overcome the uncertainty in droplet size and position when the sample is applied to the TLC plate by hand. One recent approach to automation has been the use of piezoelectric devices and inkjet printers for applying the sample. The assay combines the separation and quantification of the analyses on silica gel HPTLC plates with visualization under UV and scanning. Using this technique, the alkaloid content of different parts of the drug Panchavaktra ras finger print profile has been determined for the 3 experiments in the different times.

HPTLC of Panchavaktra ras is the preliminary quantitative analysis which shows the number of components present in the sample accurately and precisely on the basis of mild variations in $\mathrm{Rf}$ values, that can acceptable in this drug and it indicates the purity of drugs. The UV spectrum of the common peaks with large abundance appeared at Rf $0.46,0.33,0.28$, $0.30,0.41,0.49,0.56,0.57,0.59,0.99$ were found to be super imposable revealing the presence of the same constituents in all the 3 samples.
\end{abstract}

Keywords: Standardization, HPTLC, Panchavaktra ras, Herbo-Mineral Preparation.

\section{Introduction:}

The Ayurveda, Unani and Sidha system of medicines have been in practice since thousands of years. The need of quality control for those medicines is due to the fact that the preparation of drug according to the ancient method has been reduced due to the commercialization of Ayurvedic pharmacy during past era (1).

The concept of quality in those

\footnotetext{
*Corresponding author:

\section{Dr. Srinivasulu Bandari}

Consultant (Ayurveda)

National institute of Indian Medical

Heritage, Osmania Medical College building Putlibowli, Hyderabad.

Ph.No: 09347000599

E.mail:dr.vaasu@ rediffmail.com
}

days was based on physical aspects of the plant materials such as identification, colour, odour, size, type, age, etc. Today there are additional requirements, distinct in nature, for modern routine quality control of botanical raw materials, in addition to physical tests and identification i.e. chemical composition. The Govt. of India has adopted the "fingerprint" approach (2) for botanicals because it supports the traditional concept and is easy to practice at different levels of sophistication. The British Pharmacopoeia (3) has had an emphasis on using TLC and HPLC profiles to identify characteristic and active principles of herbal materials.

Panchavaktra ras, an Ayurvedic herbo-mineral formulation, consists of Parada, Gandhaka, Tankana, Pippali, 
Marica then Krshna dhattura svarasa as a Bhavana dravya and a final product as a Vati (tablet) form. It is one of the formulations mentioned in Amavata (rheumatoid arthritis). Therefore, an attempt has been made to standardize Panchavaktra ras, a Ayurvedic compound formulation based on their HPTLC fingerprint profile.
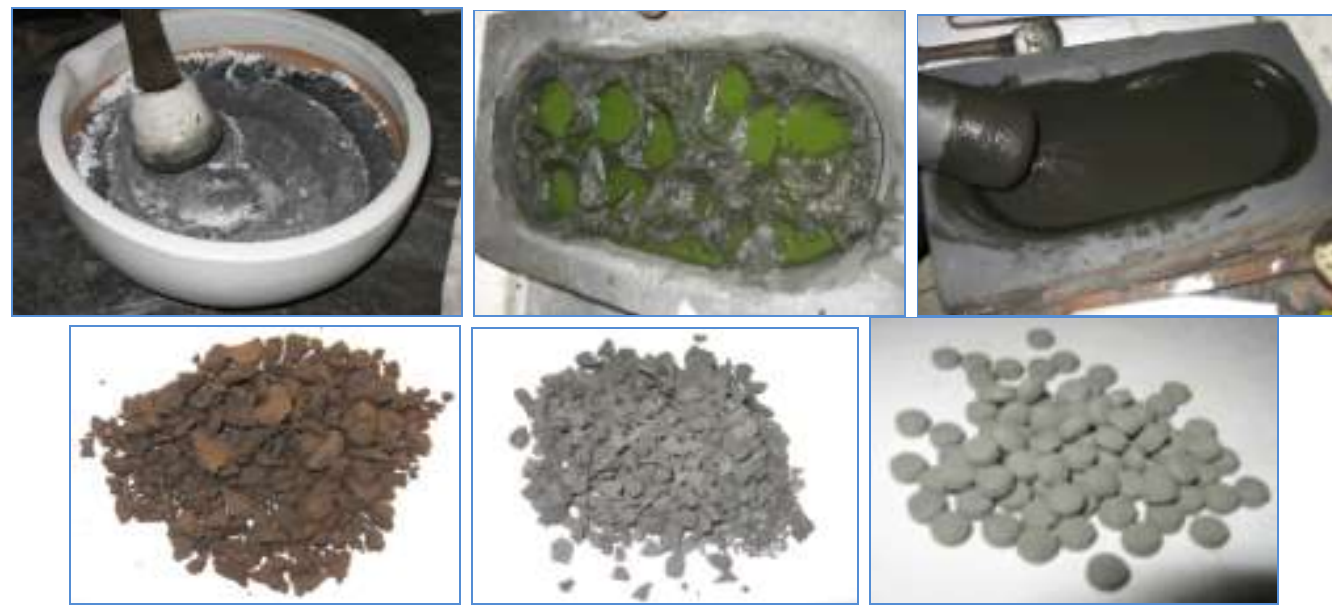

Figure 1: Panchavaktra ras preparation

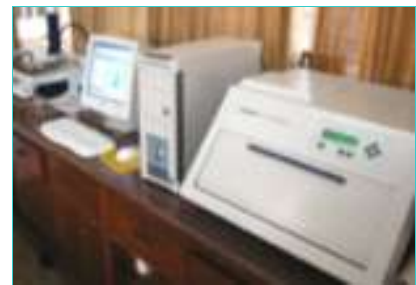

Figure 2: HPTLC Apparatus

Material and Methods:

Drug:

The present study signifies the use of TLC, HPTLC fingerprint profiles for deciding the identity, purity and strength of the Panchavaktra ras a herbo-mineral formulation using HPTLC and also standardization and authentication for fixing standards for this Ayurvedic formulation.

\section{Apparatus:}

Spotting device: Linomat IV automatic sample spotter; CAMAG (Muttenz, Swizerland)

Syringe: $100 \mu \mathrm{L}$ Hamilton (Bonadug, Swizerland)

TLC chamber: Glass twin trough chamber $(20 \times 10 \times 4)$.

Densitometer: TLC scanner 3 with CATS software; CAMAG
HPTLC Plate: $0.2 \mathrm{~mm}$ thickness and 10 cms length, 0.2 pre coated with silica gel $60 \mathrm{~F}_{254}$; Merck, Germany

pH meter: Elico Ltd., Hyderabad, India.

Flame Photometer: Digital Biomed Flame Photometer, Hyderabad.

Muffle furnace: Dolphin Industries Ltd., Mumbai.

Place of Study: LAILA Impex, Vijayawada, Andhra Pradesh.

\section{Herbo mineral materials:}

Panchavaktra ras consists of equal parts of

1. Purified Parada (4) (Mercury)

2. Purified Gandhaka (5) (Sulphur)

3. Purified Tankana (6) (Borax)

4. Barjita pippali (dried fruit of Piper longum) 
5. Barjita marica (dried fruit of Piper nigrum)

6. Bavana (maceration) with the leaf juice of krshna dhattura (Black coloured leaf of Datura metel)

All these ingredients were procured from the local market of Vijayawada, Andhra Pradesh, India and all the herbal and mineral material were thoroughly screened by experts of Rasasastra, Dr.N.R.S.Govt.Ayurvedic College, Vijayawada based on the Grahya lakshanas mentioned in the classics.

\section{Preparation of Panchavaktra ras:}

Panchavaktra ras was a Khalviya rasayana which was mentioned in the classical text of bhasavarajiyam 6th chapter of Vataroga nidana lakshana cikitsa adhyaya (7) and indicated for the Amavata (Rheumatoid arthritis). The ingredients number 1 to 3 was purified with the authentic mentioned. The ingredients number 4 and 5 fried an earthen pan on a mild flame and powdered individually and passed through 80\# sieve. In the first kajjali (black sulphide of mercury) prepared with the equal parts of purified Parada and Gandhaka in Khalva yantra (mortar pestle apparatus).

All the ingredients were mixed thoroughly in specified ratio (1 part each) and ground in the Khalva yantra with the leaf juice of Krshna dhattura to obtain a homogeneous blend. The blended mass was dried in shade. Then added starch, binding agents and lubricants (quantity mentioned in table no.1) according to the drug quantity and made tablets through the punch machine fitted with suitable die. The rolled tablets were dried in a traydryer at a temperature not exceeding $60^{\circ} \mathrm{C}$. It was packed in a tightly closed glass containers for further use. The final product of Panchavaktra ras was found to be a dark gray coloured. The same above the process this drug was prepared by the three times in different seasons.

Table. No 1: Preparation and Observation of Panchavaktra Ras

\begin{tabular}{|l|l|l|l|}
\hline Ingredients & Expt-1 & Expt-2 & Expt-3 \\
\hline Shodhita Parada & $300 \mathrm{gm}$ & $250 \mathrm{gm}$ & $200 \mathrm{gm}$ \\
\hline Shodhita Gandhaka & $300 \mathrm{gm}$ & $250 \mathrm{gm}$ & $200 \mathrm{gm}$ \\
\hline Shodhita Tankana & $300 \mathrm{gm}$ & $250 \mathrm{gm}$ & $200 \mathrm{gm}$ \\
\hline Pippali powder & $300 \mathrm{gm}$ & $250 \mathrm{gm}$ & $200 \mathrm{gm}$ \\
\hline Maricha powder & $300 \mathrm{gm}$ & $250 \mathrm{gm}$ & $200 \mathrm{gm}$ \\
\hline Total Qty. of Drug before bhavana & $1500 \mathrm{gm}$ & $1250 \mathrm{gm}$ & $1000 \mathrm{gm}$ \\
\hline $\begin{array}{l}\text { Qty. of Dhattura patra juice used for } \\
\text { bhavana }\end{array}$ & $2000 \mathrm{ml}$ & $1600 \mathrm{ml}$ & $1245 \mathrm{ml}$ \\
\hline Total Qty. of drug after bhavana & $2520 \mathrm{gm}$ & $2100 \mathrm{mg}$ & $1700 \mathrm{gm}$ \\
\hline Total Qty. Of drug after drying & $1925 \mathrm{gm}$ & $1600 \mathrm{gm}$ & $1300 \mathrm{gm}$ \\
\hline Quantity of Starch added & $50 \mathrm{gm}(2.6 \%)$ & $121 \mathrm{gm}(7.6 \%)$ & $98 \mathrm{gm} \mathrm{(7.6 \% )}$ \\
\hline Quantity of binding agents added & $192 \mathrm{gm} \mathrm{(10 \% )}$ & $64 \mathrm{gm}(4 \%)$ & $65 \mathrm{gm}(5 \%)$ \\
\hline $\begin{array}{l}\text { Quantity of Lubricants added } \\
\text { (magnesium stearate, Talc, Aerosol) }\end{array}$ & $77 \mathrm{gm} \mathrm{(4 \% )}$ & $64 \mathrm{gm} \mathrm{(4 \% )}$ & $52 \mathrm{gm} \mathrm{(4 \% )}$ \\
\hline Total weight of Drug mass & $2245 \mathrm{gm}$ & $1849 \mathrm{gm}$ & $1515 \mathrm{gm}$ \\
\hline Weight of the tablet & $150 \mathrm{mg}$ & $150 \mathrm{mg}$ & $150 \mathrm{mg}$ \\
\hline Total no of Tablets & 15000 & 12000 & 10000 \\
\hline Date of commencement & $13-11-2006$ & $26-02-2007$ & $25-02-2008$ \\
\hline Date of completion & $17-11-2006$ & $01-03-2007$ & $31-02-2008$ \\
\hline
\end{tabular}




\section{High Performance Thin Layer Liquid Chromatography (HPTLC):}

Russian botanist Tswett discovered chromatography. In 1903 he succeeded in separating leaf pigments using a solid polar stationary phase. Chromatography (Greek means "Writing in colours") is a method used basically for the separation of the components in a sample. Chromatography is an analytical method that finds wide application for the separation, identification and determination of chemical components in complex mixtures. This technique is based on the separation of components in a mixture (the solute) due to the difference in migration rates of the components through a stationary phase by a gaseous or liquid mobile phase.

\section{HPTLC Methodology:}

HPTLC is an advanced versatile chromatography technique. It provides chromatography drug finger print. It is therefore suitable for monitoring the identity and purity of drugs.

In HPTLC various steps involved are 1. Sample application 2. Chromatographic development 3. Detection of spot 4. Quantification 5. Documentation

\section{Sample Application:}

One gram of Panchavaktra ras dissolved in a $20 \mathrm{ml}$ methanol solvent and the sample is applied on pre-coated TLC plates with the automatic applicator.

\section{Chromatographic (separation):}

\section{development}

The chromatogram is developed after the solvent of the applied sample is completely evaporated. Rectangular glass chambers or twin trough chambers were used for TLC developments.

\section{Detection of spots:}

The spots are detected in U.V at wavelength $254 \mathrm{~nm}$ by spraying the dragendroff reagent and Sodium nitrite. The spots of non fluorescent compounds are also observed - fluorescent stationary phase used by the silica gel GF.

\section{Quantification and Documentation:}

Camag TLC scanner scan the chromatogram in reflectance or in transmittance mode by absorbance or by fluorescent mode scanning speed is selectable up to $100 \mathrm{~mm} / \mathrm{s}$. The portion of the scanned peaks on the recorder charts is related to $\mathrm{Rf}$ values of the spots on the spots on the layer and the peak height or area is related to the concentration of the substance on the spot.

\section{HPTLC finger printing profile:} Sample preparation:

$1 \mathrm{gm}$ of prepared sample of Panchavaktra ras tablets into a $50 \mathrm{ml}$ round bottom flask. Add $20 \mathrm{ml}$ methanol and reflux on water bath $\left(80^{\circ} \mathrm{C}\right)$ for 30 mints. Filter (what's man filter paper No. 41) and evaporate the filtrate on a water bath to a soft paste and reconstitute in 10 $\mathrm{ml}$ of methanol.

\section{Instrument method:}

Absorbent - Pre-coated Silica Gel $60 \mathrm{~F}_{254}$ plate, $0.2 \mathrm{~mm}$ thickness and $10 \mathrm{cms}$ length (Merck, Germany)

Mobile phase - Toluene Ethyl Acetate Formic acid (50:15:5)

Visualizations - Five dark spots are observed between Rf 0.25 to 0.98 under UV light $254 \mathrm{~nm}$

Development - Twin through chambers

Application position - $10 \mathrm{ml}$

Solvent front position $-76.7 \mathrm{~mm}$

Volume of the sample applied - 5 micro liters and 10 micro liters

Detection - By U.V Detection at wavelength $254 \mathrm{~nm}$ by spray with the dragendroff reagent $+\mathrm{NaNo}_{2}$ 


\section{Results and Discussion:}

\section{Panchavaktra ras sample-1:}

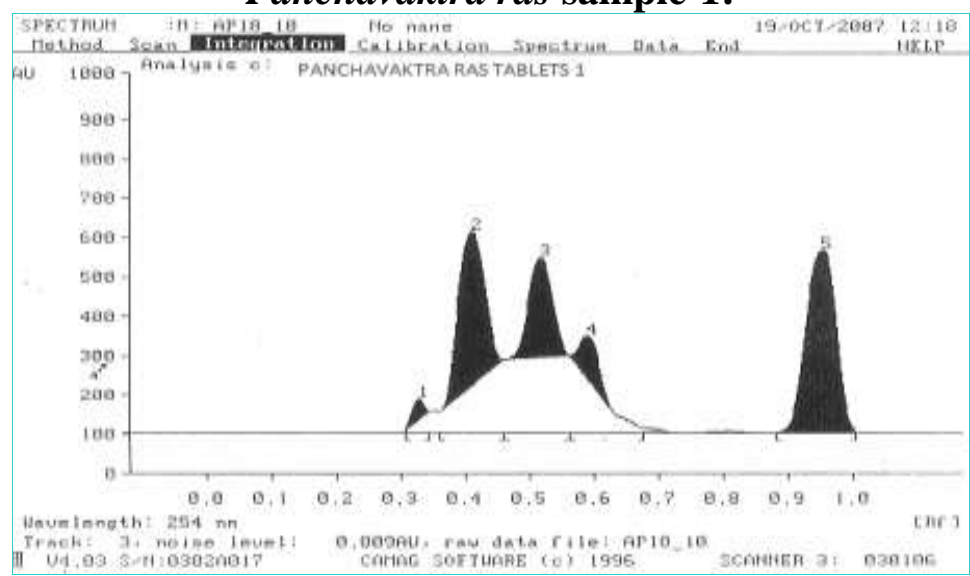

Figure 3: HPTLC fingerprinting of Panchavaktra ras sample 1

\begin{tabular}{|c|c|c|c|c|c|c|c|c|c|}
\hline \multirow{2}{*}{ peak } & \multicolumn{2}{|c|}{ start } & \multicolumn{3}{c|}{ Max } & \multicolumn{2}{c|}{ End } & \multicolumn{2}{c|}{ Area } \\
\cline { 2 - 10 } & $\mathrm{R}_{\mathrm{f}}$ & $\mathrm{H}$ & $\mathrm{R}_{\mathrm{f}}$ & $\mathrm{H}$ & $\%$ & $\mathrm{R}_{\mathrm{f}}$ & $\mathrm{H}$ & $\mathrm{F}$ & $\%$ \\
\hline 1 & 0.31 & 00 & 0.33 & 54.5 & 4.32 & 0.35 & 0.0 & 506.1 & 1.88 \\
\hline 2 & 0.36 & 0.0 & 0.41 & 387.0 & 30.69 & 0.46 & 0.0 & 8468.9 & 31.45 \\
\hline 3 & 0.46 & 0.0 & 0.52 & 249.7 & 19.80 & 0.57 & 0.0 & 4865.5 & 18.07 \\
\hline 4 & 0.57 & 0.0 & 0.60 & 112.1 & 8.89 & 0.68 & 0.0 & 1802.6 & 6.69 \\
\hline 5 & 0.89 & 0.0 & 0.96 & 457.7 & 36.30 & 1.01 & 0.0 & 11286.6 & 41.91 \\
\hline
\end{tabular}

Total height $-1261.1 \quad$ Total area $=26929.7$

Under the $254 \mathrm{~nm}$ wavelength- 5 spots were detected and starts with respect to retardation factor $0.31,0.36,0.46,0.57,0.89$. These 5 spots were maximally reached to retardation factor $0.33,0.41,0.52,0.60,0.96$ and these spots end at the Rf $0.35,0.46 .0 .57$, $0.68,1.01$.

Panchavaktra ras sample-2:

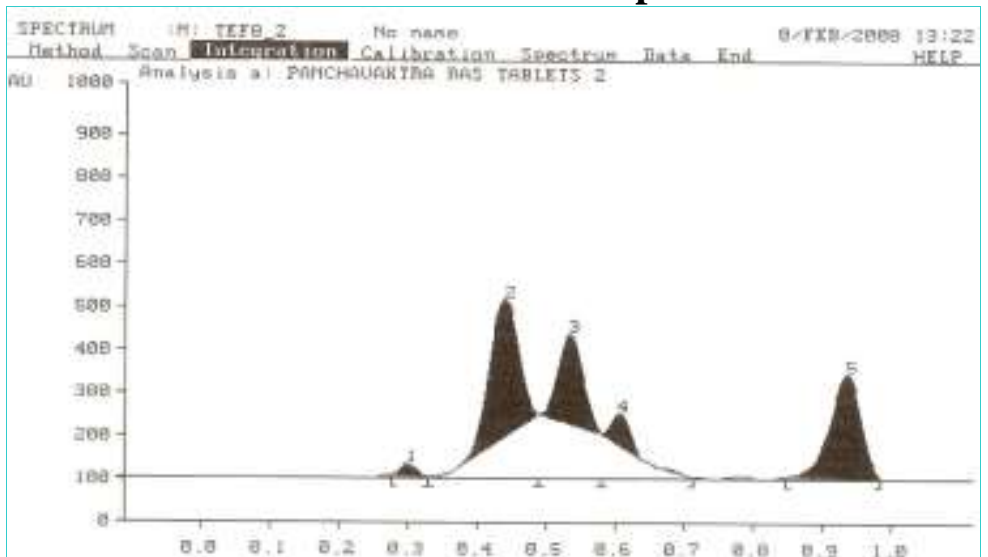

Figure 4: HPTLC fingerprinting of Panchavaktra ras sample 2

\begin{tabular}{|c|c|c|c|c|c|c|c|c|c|}
\hline \multirow{2}{*}{ peak } & \multicolumn{2}{|c|}{ start } & \multicolumn{3}{c|}{ Max } & \multicolumn{2}{c|}{ End } & \multicolumn{2}{c|}{ Area } \\
\cline { 2 - 10 } & $\mathrm{Rf}$ & $\mathrm{H}$ & $\mathrm{Rf}$ & $\mathrm{H}$ & $\%$ & $\mathrm{Rf}$ & $\mathrm{H}$ & $\mathrm{F}$ & $\%$ \\
\hline 1 & 0.28 & 3.7 & 0.30 & 28.2 & 3.30 & 0.33 & 0.0 & 358.0 & 1.91 \\
\hline 2 & 0.33 & 0.0 & 0.44 & 314.2 & 36.68 & 0.49 & 0.0 & 7393.9 & 39.35 \\
\hline
\end{tabular}




\begin{tabular}{|c|c|c|c|c|c|c|c|c|c|}
\hline 3 & 0.49 & 0.0 & 0.54 & 204.1 & 23.83 & 0.59 & 0.0 & 4024.8 & 21.42 \\
\hline 4 & 0.59 & 0.0 & 0.61 & 72.4 & 8.45 & 0.72 & 0.0 & 1122.8 & 5.98 \\
\hline 5 & 0.85 & 0.0 & 0.94 & 237.6 & 27.74 & 0.99 & 0.0 & 5891.5 & 31.35 \\
\hline
\end{tabular}

Total height -856.6 Total area $=18790.9$

Under the $254 \mathrm{~nm}$ wavelength- 5 spots were detected and starts with respect to retardation factor $0.28,0.33,0.46,0.49,0.59,0.85$. These 5 spots were maximally reached to retardation factor $0.30,0.44,0.54,0.61,0.94$ and these spots end at the $\operatorname{Rf} 0.33,0.49 .0 .59$, $0.72,0.99$.

Panchavaktra ras sample-3:

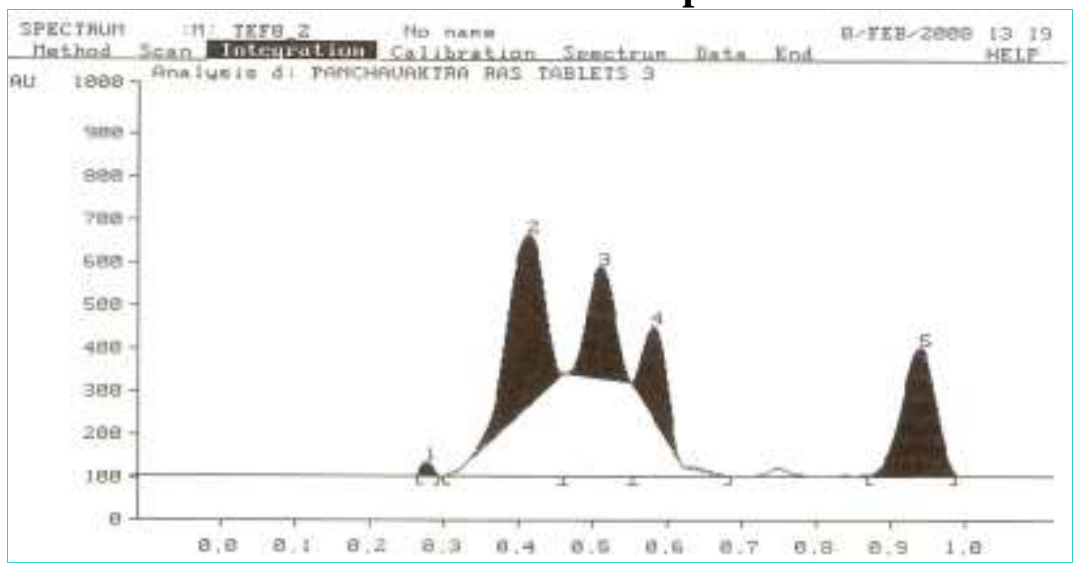

Figure 5: HPTLC fingerprinting of Panchavaktra ras sample 3

\begin{tabular}{|c|c|c|c|c|c|c|c|c|c|}
\hline \multirow{2}{*}{ peak } & \multicolumn{2}{|c|}{ start } & \multicolumn{3}{c|}{ Max } & \multicolumn{2}{c|}{ End } & \multicolumn{2}{c|}{ Area } \\
\cline { 2 - 10 } & Rf & H & Rf & H & $\%$ & Rf & H & F & $\%$ \\
\hline 1 & 0.27 & 0.0 & 0.28 & 30.0 & 2.53 & 0.29 & 0.0 & 232.1 & 0.87 \\
\hline 2 & 0.30 & 0.0 & 0.41 & 394.8 & 33.22 & 0.46 & 0.0 & 10601.8 & 39.53 \\
\hline 3 & 0.46 & 0.0 & 0.51 & 255.3 & 21.49 & 0.56 & 0.0 & 5067.1 & 18.89 \\
\hline 4 & 0.56 & 0.0 & 0.59 & 216.0 & 18.18 & 0.69 & 0.0 & 3663.0 & 13.66 \\
\hline 5 & 0.88 & 0.0 & 0.95 & 292.1 & 24.58 & 0.99 & 0.0 & 7257.7 & 27.06 \\
\hline
\end{tabular}

Total height $=1188.3 \quad$ Total area $=26821.8$

Under the $254 \mathrm{~nm}$ wavelength- 5 spots were detected and starts with respect to retardation factor $0.27,0.30,0.46,0.56,0.88$. These 5 spots were maximally reached to retardation factor $0.28,0.41,0.51,0.59,0.95$ and these spots end at the $\operatorname{Rf} 0.29,0.46 .0 .56$, $0.69,0.99$.

\section{Conclusion:}

HPTLC of Panchavaktra ras is the preliminary quantitative analysis which shows the number of components present in the sample accurately and precisely on the basis of mild variations in $\mathrm{Rf}$ values, that can acceptable in this drug and it indicates the purity of drugs.

The UV spectrum of the common peaks with large abundance appeared at $\mathrm{Rf}$ $0.46,0.33,0.28,0.30,0.41,0.49,0.56$,
$0.57,0.59,0.99$ and were found to be super imposable revealing the presence of the same constituents in all the samples (Figure 1-3). The small variation in nonmatching of the spectra may be due to the changes in the concentration of the spot in the powder samples. Panchavaktra ras, a Ayurvedic herbo mineral formulation of 5 ingredients was prepared in the clinical study and three samples HPTLC finger 
print profile developed from the study can be considered for pharmacopial standards.

\section{References:}

1. Anonymous, The Ayurvedic Formulary of India, Govt. of India, Ministry of Health and Family Welfare, New Delhi,1976.

2. Lazaowych NJ, Pekos P, Use of fingerprinting and marker compounds for identification and standardization of Botanicals, Dug Information Journal, 32, 1998, page no: 497-512.
3. British Herbal Pharmacopoeia, British Herbal Medicine Association, 1996.

4. Rasa Tarangini by Pranacharya Sri Sadananda Sharma edited by Pandita Kashinath Shastry published by Motilal Banarasidas, New Delhi. Reprint: 2004; ISBN: 81-208-2542-X; Page no: 22

5. Ibid: Page no: 177

6. Ibid: Page no: 319

7. Basavarajeeyam, by Basava Raju, edited by Puvvada Suryanarayana, ABS Publsihers, Rajahmundry, 1998 (telugu); page no: 309 